\title{
A\&L
}

ISSN 2709-0205

Vol 1 Issue 1 (2020)

\section{Functional age and residual working capacity in pensioners}

\author{
Oleksandr Poliakov \& Olena Tomarevska \\ State Institution “D. F. Chebotarev Institute of Gerontology NAMS of Ukraine”, Kyiv, Ukraine,
}

Correspondence: tomarevskaya@gmail.com

Received: 24.01.2020; Accepted: 25.01.2020; Published: 07.07.2020

\begin{abstract}
This investigation is dedicated to clarifying of physiological mechanisms of labor activity in subjects of a different gender and age with the purpose of a theoretical background of rational usage of human residual performance and rehabilitation of his health. When analyzing the tightness of the relationships, there is a stronger relationship between the residual performance and the calendar age than the rate of functional aging and calendar age. The study of concomitant influencing factors throughout life has been shown that the presence of labor or family migration within the region, within and between states; as well as indicators of the length of service, year, age, and reasons for retirement do not have reliable correlation with the rate of aging. Reliable correlation associations were found with continued retirement at the time of the study; with the year of termination of work; and the size of the total income of the examined individuals - associations in comparison with the relationship with the calendar age have a weaker connection with the rate of aging. With indicators of the class of tension and severity, type of work, class of intensity, class for differentiation of labor according to the ILO classification. Muscle strength and endurance in the women have expressed age dynamics. The muscle strength of the women is significantly slashed at 3035 of years, and the muscle endurance remains stable up to 55-year's age. For the men the dynamics of the muscle strength and endurance have no obvious age trend, and mostly depend from lifestyle, physical and labor activity. In functionally young subjects the working physical work capacity is $15-20 \%$ higher, compared to an average level, observed when the functional and calendar ages coincide. The age-related decline the physical working capacity in the older workers is decelerated owing to the selection of those who are functionally young and the elimination of those who age prematurely. The physiological capabilities that determine $47.54 \%$ of the actual performance of people aged $60-89$ years are reliably due to accelerated aging. Studies have shown high information content of using the indicator of residual performance in people over 60 years of age. A study of residual performance in people over 60 years of age showed that close to $57 \%$ of elderly people and $96.7 \%$ of senile people need ergonomic innovations in work and life to increase physical independence from outside help and compensate for age-related decline of working capacity.
\end{abstract}

Key words: Biological age, residual working capacity, elderly workers, ageing, hand grip strength.

Medical scientific studies dealing with actual population and samples investigation are shows an increasing tension of the functional systems in person during physical, cognitive and professional the conditions of activity. The heterochronous character of human aging remains relevant [1]. In modern manufacture conditions, person does not work on the top level of his own capacity, but uses part of them, evenly distributing them throughout the working day. The pace of aging characterizes the speed of dynamics of processes of age-related involution in human body. A quantitative assessment of the pace of aging in human is possible due to a comparison between the values of the functional and calendar age. Determining the 
functional age and pace of aging of a person is a very important task of preventive gerontology and geriatrics [2]. Functional age is a sanological category that reflects the level of human health. In everyday medical practice, unfortunately, few doctors use new diagnostic research methods, including determining the rate of aging. The main reason for this is the lack of medical equipment and apparatus in simple clinics. The problem of studying the functional (biological) age and rate of aging of the human is very important in medical diagnostics [3]. This concept of healthy ageing inspires a new focus for health care in older age - a focus on optimizing people's intrinsic capacity and functional ability as they age [11].

\section{Methods}

163 persons considered for this study. We have studied anthropometric characteristics, parameters of respiration, physical performance, psychomotor activity, sensory skills and mental activities. In addition, pace of functional ageing studied in 120 persons aged 60-89 years and 43 men aged 20-30 years. We have also analyzed the professional work history, social status and factual nutrition of the surveyed older people. Assessment of Functional Age and Pace of Aging in Persons.

To determine the functional age and the rate of aging, it is sufficient to register:

1. Tonometry measurement the arterial systolic pressure (ASP) and arterial diastolic pressure (ADP) (mm Hg).

2. Spirometry measurement the vital capacity of the lungs (VCL) a in a steady-state conditions (liters).

3. The time of inhalation breath-hold (IBH) and exhalation breath-hold (EBH) (seconds).

4. The time of left leg standing with closed eyes (LLS) (seconds).

5. Steady-state heart rate (S-SHR), per minute.

6. Heart rate after 20 sit-ups (HRSU), per minute.

The pace of aging in human (PA) is calculate by the formula:

PA $=($ ASPf $/$ ASPt + ADPf / ADPt + S-SHRf / S-SHRt +HRSUf / HRSUt

$+\mathrm{VCLt} / \mathrm{VCLf}+\mathrm{IBHt} / \mathrm{IBHf}+\mathrm{EBHt} / \mathrm{EBHf}+$ LLSt / LLSf) / N

According

$\mathrm{f}$ - actual value of the parameters;

$\mathrm{t}$ - tabular value of the parameters;

$\mathrm{N}$ is the number of indicators used in the formula.

The table values are means of the age depending parameters in person (male and female):

\begin{tabular}{|l|l|l|l|l|l|l|l|l|l|l|l|l|l|l|}
\hline & \multicolumn{9}{|c|}{ Male } & \multicolumn{6}{|c|}{ Female } \\
\hline Age & 20 & 30 & 40 & 50 & 60 & $70<$ & Age & 20 & 30 & 40 & 50 & 60 & $70<$ \\
39 & 49 & 59 & 69 & & & 29 & 39 & 49 & 59 & 69 & \\
\hline ASP & 120 & 120 & 130 & 130 & 120 & 120 & ASP & 120 & 120 & 130 & 130 & 120 & 120 \\
\hline ADP & 70 & 70 & 70 & 80 & 80 & 80 & ADP & 70 & 70 & 70 & 80 & 80 & 80 \\
\hline S-SHR & 60 & 70 & 70 & 70 & 70 & 75 & S-SHR & 60 & 70 & 70 & 70 & 70 & 75 \\
\hline HRSU & 120 & 130 & 140 & 150 & 150 & 150 & HRSU & 120 & 130 & 140 & 150 & 150 & 150 \\
\hline VCL & 3,5 & 3,4 & 3,0 & 2,9 & 2,6 & 2,0 & VCL & 3,0 & 2,8 & 2,8 & 2,0 & 1,8 & 1,8 \\
\hline IBH & 90 & 90 & 80 & 60 & 40 & 30 & IBH & 60 & 60 & 40 & 30 & 20 & 20 \\
\hline EBH & 60 & 60 & 40 & 30 & 20 & 20 & EBH & 40 & 40 & 20 & 20 & 18 & 18 \\
\hline LLS & 60 & 60 & 40 & 30 & 20 & 10 & LLS & 30 & 30 & 20 & 18 & 18 & 10 \\
\hline
\end{tabular}

The value pace of the aging more than 1.1 reflects the acceleration of pace aging in person; the pace of the aging is less than 1 - means the slowed-down pace of aging in person functional younger, the values 1-1.1 - reflects the physiological pace of aging. 
The functional age of organism is determined by the formula:

$\mathrm{FA}=\mathrm{PA} * \mathrm{CA}$

According:

FA - the functional age of organism; CA - the chronological age of person; PA - pace of aging.

The positive difference between chronological age and functional age (- 5.1 years and more) are can be used to assess a given individual person functional younger.

Deviation of the functional age by \pm 5 years from the calendar reflects physiological aging, by $+5-+10$ years - premature aging, more than +10 years - accelerated aging in functional older person [4].

Residual capacity of human - is the actual functional state of a person aged 60 years or older, can successfully perform professional, industrial, everyday tasks and is valued as a percentage of capacity of the healthy young workers (aged less than 30 years).

To evaluate the objective function uses the following indicators: the level of cognitive clinical features scale (MMSE) [5,6], the amount of self-service (by Barthel index) [7]; hand grip strength (the sum strength of the left and right hand); assessment of auditory and visual, motor abilities and success of the respective correction; static balancing; tactile productivity; auditory productivity; successful work with the touchpad; visual productivity (number of correct answers per minute); the number of correct answers in the test for the missed number per minute (computer model for evaluating intellectual efficiency); the maximum number of clicks on the button PC computer model of tapping-test; short memory of human; vital lung capacity; the average time visual-motor response in milliseconds (computer model of the test); Mode of the time variability of visual-motor response in milliseconds; average response time in the test evaluation of mental capacity.

Formula

$$
R C=\left.\left(\frac{\prod_{k=1}^{3} A_{k}}{x_{5}}+\sum_{i=1}^{n=10} a_{i}+\frac{1}{\sum_{i=1}^{n=3} b_{i}}\right)\right|_{\text {const }}
$$

A1 - MMSE, A2 - Barthel index, (A3 ) - hands grip strength, x5 - assessment of sensory and motor abilities, $\alpha 1$ - left leg standing, $\alpha 2$ - productivity tactile, $\alpha 3$ - auditory memory, $(\alpha 4, \alpha 5)$ - work (one and double click) with the touch panel, $\alpha 6$ - the speed in the test of attention, $\alpha 7$ - speed of combinatorial test, $\alpha 8$ - the maximum number of clicks on the PC, $\alpha 9$ - the percentage short-term memory, $\alpha 10$ - vital capacity, b1 - the average time visual-motor response in milliseconds for computer testing; b2 - mode variability time visual-motor response, in milliseconds, b3 - the average response time in the test evaluation of intellectual efficiency; $\mathrm{k} \approx$ (for men 378.925 and for women 231.775).

Formula to quantify the residual performance, which reflects the overall efficiency parameters used in the work of modern jobs by optimizing physiological human capabilities to improve efficiency at work and home, and in daily activities (representation formula for the determination coefficient $\mathrm{d}=94 \%$, multiple regression coefficient $R=0.972$ ) [10].

\section{Results and Discussion}

When analyzing the tightness of the relationships, there is a stronger relationship between the residual performance and the calendar age $(\mathrm{r}=-0.784 ; \mathrm{p}<0.001)$ than the rate of functional aging and calendar age $(\mathrm{r}=$ $0.289 ; \mathrm{p}<0.01)$.

The study of concomitant influencing factors throughout life has been shown that the presence of labor or family migration within the region, within and between states; as well as indicators of the length of service, year, age, and reasons for retirement do not have reliable correlation with the rate of aging. Reliable correlation associations were found with continued retirement at the time of the study (after 60 years) $(\mathrm{r}=$ 0.253; $\mathrm{p}<0.05)$; with the year of termination of work $(\mathrm{r}=-0.251 ; \mathrm{p}<0.05)$; and the size of the total income of the examined individuals $(r=-0.214 ; p<0.05)$ - associations in comparison with the relationship with the calendar age have a weaker connection with the rate of aging. With indicators of the class of tension $(r=-$ $0.055)$ and severity $(r=0.120)$, type of work $(r=0.055)$, class of intensity $(r=0.099)$, class for differentiation of labor according to the ILO classification $(r=0.087)$ - not reliable correlation with the rate of aging in the general cohort of elderly people (tab. 1). 
The of occupational and labor parameters influence on the pace of functional aging and residual performance in people over 60

\begin{tabular}{|l|l|l|}
\hline & Pace of Aging & Residual working capacity of the elderly people \\
\hline Type of Work & 0.0554 & -0.1698 \\
\hline $\begin{array}{l}\text { Class of } \\
\text { tension }\end{array}$ & -0.0553 & $\mathbf{0 . 2 3 6 6 ^ { * }}$ \\
\hline $\begin{array}{l}\text { Class severity } \\
\text { of labor }\end{array}$ & 0.1196 & $\mathbf{- 0 . 3 0 0 \mathbf { 1 } ^ { * * }}$ \\
\hline $\begin{array}{l}\text { Class of } \\
\text { intensivity }\end{array}$ & 0.0988 & $\mathbf{- 0 . 3 4 0 0 ^ { * * * }}$ \\
\hline
\end{tabular}

Notes: ${ }^{*}-\mathrm{p}<0.05 ; * *-\mathrm{p}<0.01 ; * * *-\mathrm{p}<0.001$

An analysis of the close relationships between the aging pate and physiological indicators revealed a weakening of the correlations of the static strength of the right $(\mathrm{r}=-0.241 ; \mathrm{p}<0.05)$ and left hand $(\mathrm{r}=-0.253$; $p<0.05)$ in comparison with the correlation association with the calendar age $(r=0.289 ; p<0.01)$ in people over 60 years of age. However, associations with the rate of aging by functional age and the general indicator of cognitive function research (according to MMSE), as well as the percentage of body fat, peak flowmetry, and residual overall performance exceed the tightness of ties with calendar age. A reliable contribution to the pathological acceleration of the aging rate was made by indicators of lung capacity, breath holding on inhalation and exhalation, and especially the indicator of static balancing ( $28.3 \%$ could not complete this test for more than 0.5 seconds), see table 2. It should be noted that the correlation between the rate of aging and static strength of the hands, as well as the indicator of cognitive capabilities, vital capacity of the lungs, breath holding on inhalation and exhalation in the group after 75 years becomes unreliable and weaker than in the age group 60 - 74 years. Physiological dependence is statistically confirmed: the higher the aging rate in terms of functional age, the lower the percentage of residual overall performance is determined in people after 60 years.

The peak flowmetry indicator has a closer relationship with the rate of aging in people after 60 than the VC. This indicator reflects the functional ability of external respiration in compensating for age-related changes in the cardiovascular and musculoskeletal systems in people after 60 years of age [8].

Table 2

Correlation constellations of the rate of aging and physiological indicators in different cohorts of elderly

\begin{tabular}{|l|l|l|l|}
\hline \multicolumn{1}{|c|}{ people } \\
\hline $\begin{array}{l}\text { Mini Sental State } \\
\text { Examination (MMSE) }\end{array}$ & $-0.331^{* * *}$ & $\begin{array}{l}\text { Index of aging pace of } \\
\text { people } 60-74 \text { years. }\end{array}$ & $\begin{array}{l}\text { The pace of aging in people } 75-89 \\
\text { years old. }\end{array}$ \\
\hline Right hand grip strength & $-0.241^{*}$ & $-0.543^{* * *}$ & -0.214 \\
\hline Left hand grip strength & $-0.253^{*}$ & $-0.304^{*}$ & -0.089 \\
\hline Body Fat percent & $0.316^{* *}$ & $-0.320^{*}$ & -0.101 \\
\hline Vital Lung Capacity & $-0.325^{* * *}$ & $0.334^{* *}$ & $0.291^{*}$ \\
\hline Pick expiratory flow & $-0.509^{* * *}$ & $-0.457^{* * *}$ & -0.186 \\
\hline Breath holding inhaling & $-0.327^{* * *}$ & $-0.485^{* * *}$ & $-0.514^{* * *}$ \\
\hline Breath holding exhaling & $-0.337^{* * *}$ & $-0.473^{* * *}$ & -0.178 \\
\hline $\begin{array}{l}\text { Left leg standing with } \\
\text { closed eyes }\end{array}$ & $-0.276^{*}$ & $-0.501^{* * *}$ & -0.187 \\
\hline $\begin{array}{l}\text { Residual Working } \\
\text { Capacity }\end{array}$ & $-0.364^{* *}$ & $-0.355^{* *}$ & $-0.323^{*}$ \\
\hline Age chronological & $0.289^{* *}$ & $-0.323^{*}$ & $-0.293^{*}$ \\
\hline
\end{tabular}

Notes: ${ }^{*}-\mathrm{p}<0.05 ;{ }^{* *}-\mathrm{p}<0.01 ; * * *-p<0.001$

In our study, we determined that the cohort of elderly people is characterized, on average, by the aging pace of chronic diseases examined in remission of $1.60 \pm 0.13$, and for people in old age $2.40 \pm 0.28$, 
these indicators reflect the total acceleration of the aging pace with calendar age (Fig. 1). The prevalence of the accelerated (pathological) pace of aging is observed due to age-dependent processes on the part of the cardiovascular system in the examined individuals.

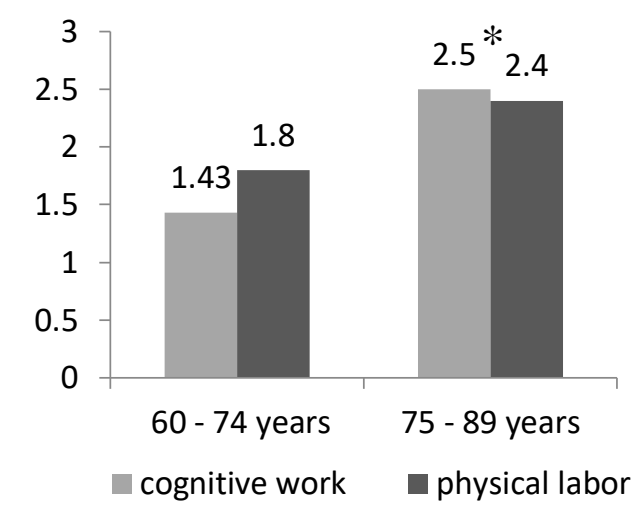

Figure 1. Acceleration of the pace of aging in terms of functional age in people older than 60 years, taking into account the calendar age and labor history, $\mathrm{p}<0.01$.

A sharp decrease in the percentage of the examined individuals with a slow and physiological pace of aging in old age was revealed (Fig. 2).

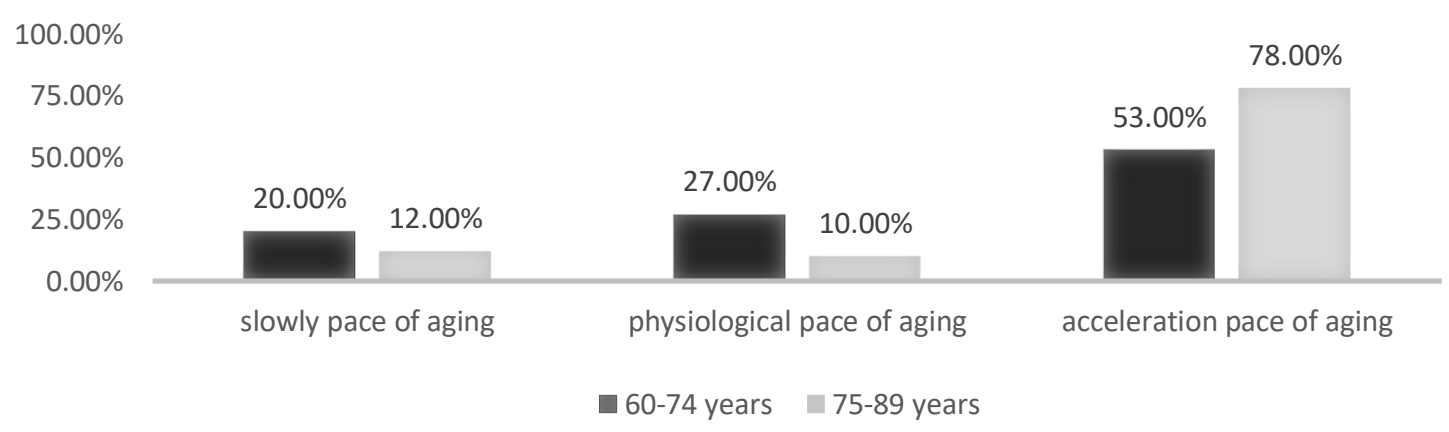

Figure 2. Percent distribution among the examined elderly and senile people by the type of aging pace due to functional age

In the elderly group, the indicator of residual overall performance was $64.63 \pm \%$, while in the group of senile age $30.45 \pm \%$ (Fig. 3). A decrease in the percentage of the total residual working capacity of people of old age was $34 \%$ relative to the elderly. We analyzed the trend lines of the pace of aging, residual overall working capacity and type of work (mental and physical labor), revealed a greater sensitivity of the indicator of residual total working capacity to the ratio of the calendar age than the rate of aging (Fig. 1, Fig. 3). For people with mental labor, a decrease in total residual working capacity by $35 \%$ in old age is characteristic, and for people with physical labor by $32.16 \%$, taking into account the fact that the total residual working capacity of people with physical labor in old age is reduced by $8.68 \%$ in a comparison with people of this age group with a history of mental work. These features are related to the fact that the indicator of residual overall performance includes a wider range of vectors of activity of a person of an elderly and (or) senile age, in relation to the similar fulfillment of tasks by people at a young age. 


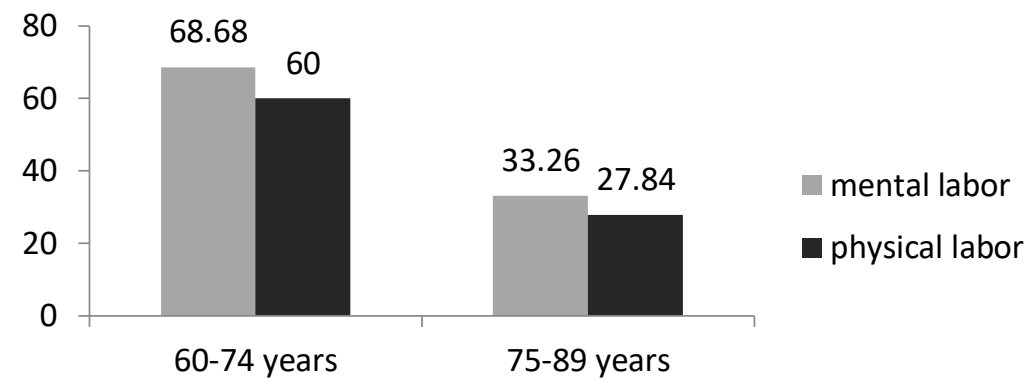

Figure 3. Change in the percentage of residual overall performance in people in age groups older than 60 years with predominantly mental and physical labor in a history of work

When assessing functional parameters and anthropometric data, closer relationships were found between the indicator of residual performance in people after 60 years of age, in contrast to the rate of functional aging (Tab. 3).

Table 3

The relationship of functional indicators in people of retirement age

\begin{tabular}{|l|l|l|}
\hline & Pace of functional aging & Residual working capacity \\
\hline Hand Grip Strength (right) & $-0.241^{*}$ & $\mathbf{0 . 7 9 3 ^ { * * * }}$ \\
\hline Hand Grip Strength (left) & $-0.253^{*}$ & $\mathbf{0 . 8 0 4 ^ { * * * }}$ \\
\hline Vital Lung Capacity & $-0.325^{* * *}$ & $\mathbf{0 . 6 6 9 ^ { * * * }}$ \\
\hline Peak Expiratory Flow & $-0.509^{* * *}$ & $\mathbf{0 . 5 8 6 ^ { * * * }}$ \\
\hline Breath Holding Inhaling & $-0.327^{* * *}$ & $\mathbf{0 . 6 3 3 ^ { * * * }}$ \\
\hline Breath Holding Exhaling & $-0.337^{* * *}$ & $\mathbf{0 . 6 1 8 ^ { * * * }}$ \\
\hline Left Leg Standing with Closed Eyes & $-0.276^{*}$ & $\mathbf{0 . 5 0 4 ^ { * * * }}$ \\
\hline Body Fat percent & $\mathbf{0 . 3 1 6 ^ { * * }}$ & 0.050 \\
\hline Body Mass Index & -0.040 & $\mathbf{0 . 2 3 3 ^ { * }}$ \\
\hline MMSE & $-0.331^{* * *}$ & $\mathbf{0 . 7 0 0 ^ { * * * }}$ \\
\hline Age chronological & $0.289^{* *}$ & $\mathbf{- 0 . 7 8 3 ^ { * * * }}$ \\
\hline
\end{tabular}

Notes: ${ }^{*}-\mathrm{p}<0.05$; $^{* *}-\mathrm{p}<0.01$; $^{* * *}-\mathrm{p}<0.001$

When analyzing the physiological capabilities of a person after 60 years, using the capabilities of young people for $100 \%$, we received a sharp decrease in the quantitative assessment of the residual performance of senile people (Fig. 4). 


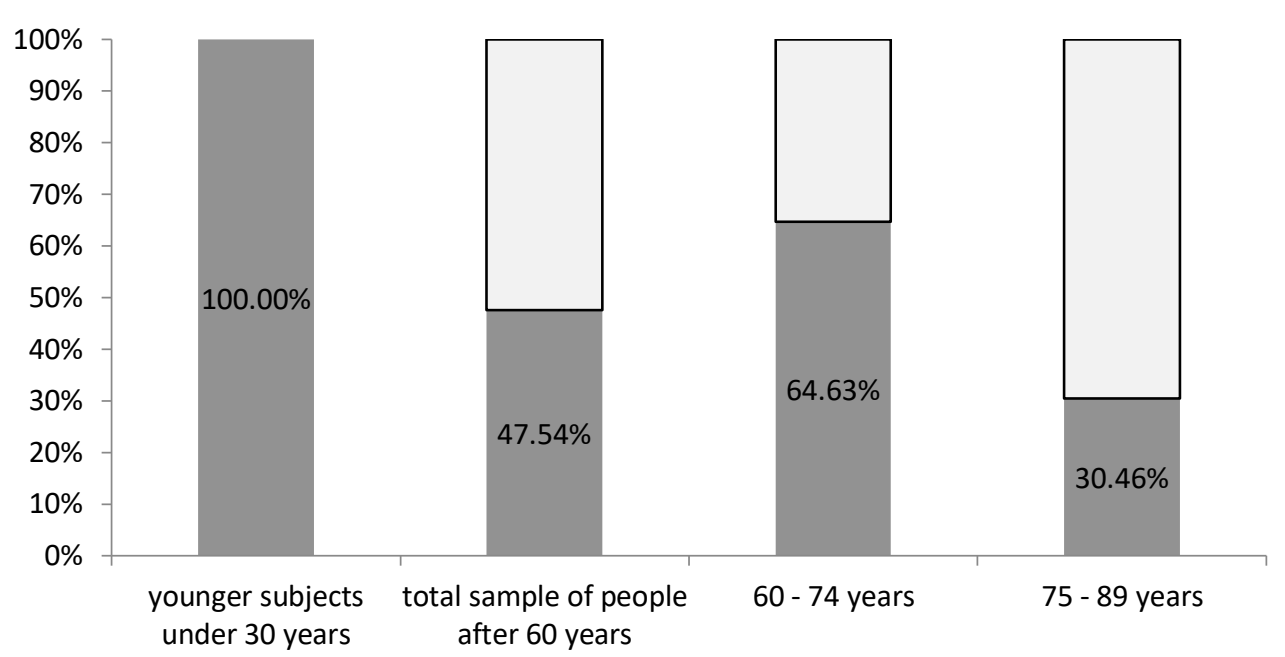

Figure 4. Physiological abilities of persons after 60 years providing residual performance

In working with modern devices, both in enterprises and in everyday life, a modern person in old and old ages is faced with increased requirements for his sensory capabilities of a visual auditory analyzer, as well as quick processing of information received. We analyzed the rate of aging and psychophysiological parameters obtained from the tasks performed by the subjects using a laptop, touch panel and Landolt's correction tables. A subjective assessment of one's state of health directly correlates with the rate of aging in a sample of elderly people (Tab. 4).

Table 4

Correlation constellations of the rate of aging and psychophysiological indicators in different cohorts of people over 60 years

\begin{tabular}{|l|l|l|l|}
\hline & $\begin{array}{l}\text { Pace of Aging in } \\
\text { Total Sample }\end{array}$ & $\begin{array}{l}\text { Pace of Aging in } \\
\text { people 60-74 } \\
\text { years }\end{array}$ & $\begin{array}{l}\text { Pace of Aging in people } \\
75-89 \text { years }\end{array}$ \\
\hline Health Self-esteem & $0.216^{*}$ & $0.259^{*}$ & 0.149 \\
\hline Visual Sensor capacity & $-0.322^{* *}$ & -0.170 & $-0.588^{* * *}$ \\
\hline Visual Sensor test efficiency & $-0.361^{* * *}$ & -0.208 & $-0.539^{* * *}$ \\
\hline Attention rate & $0.208^{*}$ & $0.438^{* * *}$ & -0.238 \\
\hline Hearing productivity right answers & $-0.399^{* * *}$ & -0.224 & $-0.423^{* * *}$ \\
\hline $\begin{array}{l}\text { Successful operation (tapping) with } \\
\text { one touchpad }\end{array}$ & $-0.340^{* * *}$ & $-0.337^{* *}$ & $-0.297^{*}$ \\
\hline $\begin{array}{l}\text { Errors when working (tapping) } \\
\text { with the one touch panel }\end{array}$ & $0.213^{*}$ & $0.392^{* *}$ & $-0.270^{*}$ \\
\hline $\begin{array}{l}\text { Successful operation (double click) } \\
\text { with one touchpad }\end{array}$ & $-0.318^{* *}$ & $-0.281^{*}$ & $-0.340^{* *}$ \\
\hline $\begin{array}{l}\text { Tapping Test, the First Period } \\
\text { (During 5 Seconds) }\end{array}$ & $-0.222^{*}$ & $-0.286^{*}$ & -0.201 \\
\hline $\begin{array}{l}\text { Tapping Test, the Second Period } \\
\text { (During 5 Seconds) }\end{array}$ & $-0.221^{*}$ & $-0.367^{* *}$ & -0.154 \\
\hline $\begin{array}{l}\text { Tapping Test Total during 30 } \\
\text { seconds }\end{array}$ & $-0.224^{*}$ & $-0.319^{*}$ & -0.174 \\
\hline
\end{tabular}

Notes: ${ }^{*}-\mathrm{p}<0.05 ;^{* *}-\mathrm{p}<0.01 ;{ }^{* * *}-\mathrm{p}<0.001$

We were not able to identify reliable correlations between the rate of aging in the general sample after 60 years with such psychophysiological indicators as optimistic mood in life, motivational behavioral factors (life satisfaction), latent period of the visual-motor reaction and its spectral variability indices, random access memory, indicator mental performance. Correlation analysis revealed a prevalence of relationships with the rate of aging of the performance indicators of the visual, auditory analyzer, focus, tapping test. The tapping test during the adaptation period of the first period (during 5 seconds) among people from the group of $60-74$ years is higher than the slower pace of functional aging. The second period (during 5 seconds) of the tapping test reflects the level of human performance in this case means working 
ability skills on laptop. Since if we examined the tapping test indicators the paper version (classic), the obtained data would be higher for both young and elderly and senile age. For a total of 30 seconds, the tapping test reflected in our study the interaction between modern technology (processor speed, keyboard ergonomics, key sensitivity) and a person (work speed, attention, consideration parameters, vision, hearing, tempo, time, ability to adapt to an unfamiliar device and task) in the studied age groups.

The upgrade process of mastering the new ergonomic possibilities of computerization in everyday life, everyday life and in a professional way, an elderly person faces difficulties in learning and retraining, this has been repeatedly emphasized in the works of leading scientists in Ukraine [9]. Thus, our study revealed that for people over 75 years of age, the significant contribution of the productivity factor of the visual and auditory analyzer is in relation to the pace of aging than in the age group $60-74$ years. At the same time, the elderly group is characterized by a greater contribution of the attention factor to the relationship with the pace of aging. The pace of aging is reflected in the indicators of success with the touch panel, reliable correlation in both age groups. Moreover, in the group of senile age, there is a connection with the assumption of fewer errors with this sensor device, the higher the aging rate. This phenomenon is probably due to the fact that the respondent focuses less on the task, which is better reflected in success. It should be noted that in the group of senile age, $27 \%$ of the examined people completed the task while working with the one touch panel, and in the elderly group they were able to complete the tasks - $90 \%$.

When ranking the physiological capabilities of people over the age of 60 , we were able to obtain, in percentage terms (relative to the capabilities of young people), a qualitative characteristic of residual capacity for understanding which geotechnologies are required for correction (Fig. 4). Thus, it was found out:

$100 \%-90 \%$ characterizes the indicator of residual performance, as appropriate to the capabilities of young people;

$89 \%-70 \%$ are characterized by the indicator of residual disability, how it is possible to use labor in production, but the class of tension and severity should not exceed class 2;

$69 \%-50 \%$ describes how it is possible to increase the efficiency of activities with the help of gerontechnology;

$49 \%-20 \%$ is characterized as an overstrain of the functional systems of the body, require a deeper correction;

$19 \%-1 \%$ need technologies for supervision, support and "tips", social activity is narrowing.

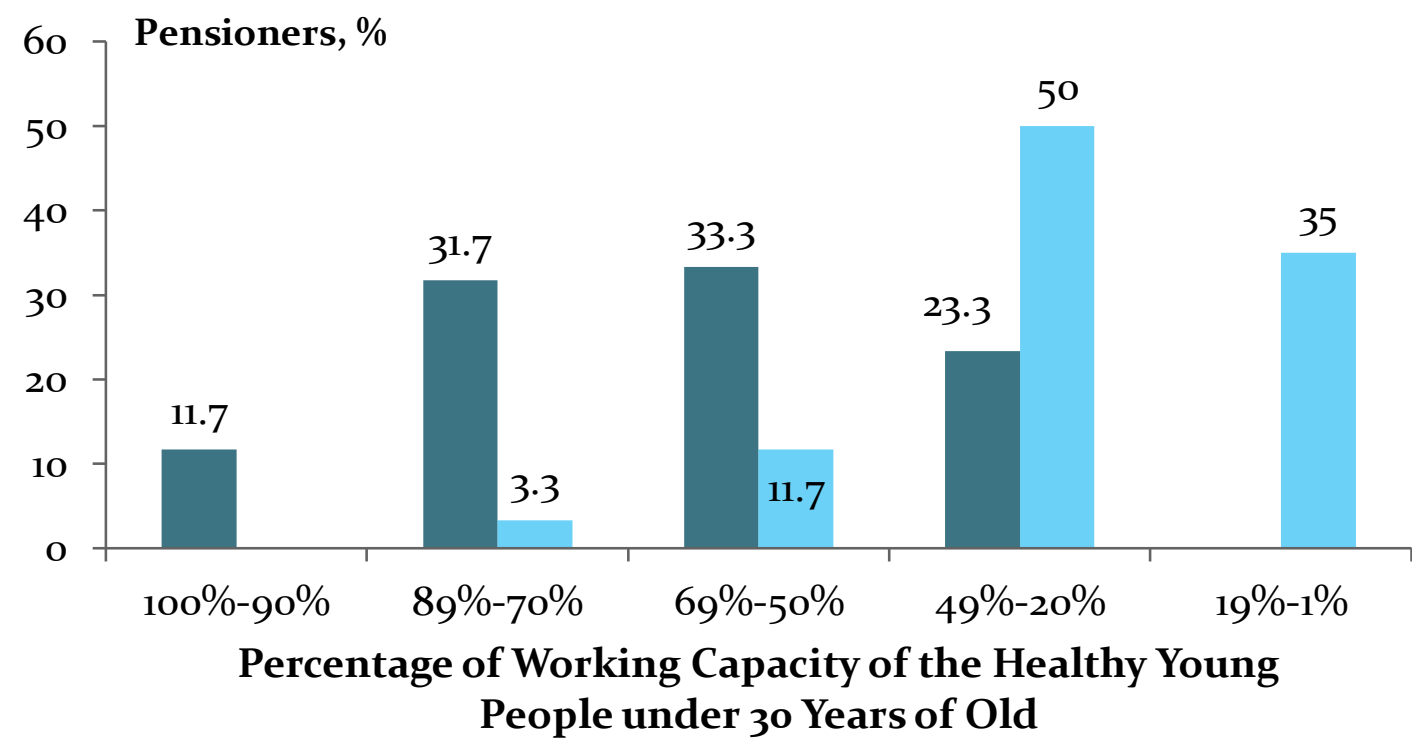

6o - 74 years

$75-89$ years

Figure 5. Age features of the residual performance of people over the age of 60 


\section{Conclusion}

The physiological capabilities that determine $47.54 \%$ of the actual performance of people aged $60-89$ years are reliably due to accelerated aging. Studies have shown high information content of using the indicator of residual performance in people over 60 years of age. A study of residual performance in people over 60 years of age showed that close to $57 \%$ of elderly people and $96.7 \%$ of senile people need ergonomic innovations in work and life to increase physical independence from outside help and compensate for agerelated decline of working capacity.

Author Contributions: All authors participated equally in writing this commentary.

Conflicts of Interest: The authors declare no conflict of interest.

Information about Authors:

Olena Tomarevska - MD, PhD, Senior Scientific Researcher of Laboratory Occupational-Labor Rehabilitation, Social Gerontology and Public Health Department; https://orcid.org/0000-0002-4282-6914

Oleksandr Poliakov - MD, PhD, Head of Laboratory Occupational-Labor Rehabilitation, Social Gerontology and Public Health Department; https://orcid.org/0000-0001-7466-9127 


\section{References}

1. Kolodchenko, V.P. Biolohichnyy vik khvorykh na osteoartroz i osteoporoz Biological Age of Patients with Osteoarthrosis and Osteoporosis [Biological Age of Patients with Osteoarthrosis and Osteoporosis]. Bulletin of orthopedics, traumatology and prosthetics. Kyiv 2010, 64, 1, 71 - 75.

2. Kishkun, A.A. Biologicheskiy vozrast i protsessy stareniya: otsenka $i$ kontrol' vozmozhnostey: rekomendatsii dlya vrachey [Biological Age and Aging Processes: possibilities estimation and control: Guidelines for physicians]. GEOTAR - Media: Moscow, 2008, p 976.

3. Ahaladze, N.G. \& Yena, L. M. Biologicheskiy vozrast cheloveka: otsenka tempa stareniya, zdorov'ya i zhiznesposobnosti [Human Biological Age: Estimation of the Pace of Aging, Health and Vitality]. VTF Perun: Kyiv, Irpen, 2009, p 224

4. Poliakov, O.A.; Korobeynikov, G.V. Metodika otsenki skorosti stareniya i funktsional'nogo vozrasta organizma [Method of Estimation of Rate of Aging and Functional Age of Organism. Patient 21851A, MKI 5 A 61 B5/00, no 95020586, apl 09.02.95 ]. Ukraine, 1998, 2.

5. Mankovskyi, N.B.; Bachinskaya, N.Yu. Cognitive activity in Aging. Problems of aging and longevity (in Russian). Kyiv 2008, 17, 4, $444-450$.

6. Bezrukov, V.V.; Bachynska, N.Yu.; Choline, V.O. et al. Syndrom lehkoyi kohnityonoyi nedostatnosti pry starinni [Syndrome of mild cognitive impairment in aging]. Methodical recommendations (in Ukrainian). Kiev, 2007, p 36.

7. Belova, A.N., Schepetova, O.N. Vesy, Testy i oprosniki v meditsinskoy reabilitatsii [Scales, tests and questionnaires in medical rehabilitation]. Antidor: Moscow, 2002, p 440

8. Korkushko, O.V.; Chebotarev, D. F.; Chebotarev N. D. Vozrastnyye izmeneniya v dykhatel'noy sisteme pri starenii i ikh rol' $\mathrm{v}$ razvitii bronkholegochnoy patologii [Age-related changes in the respiratory system during aging and their role in the development of bronchopulmonary pathology]. Ukr. pulmonol. Journal (in Russian). Kyiv 2005, 3, 49, 38-43.

9. Trakhtenberg, I. \& Poliakov, A. Ocherki po fiziologii i gigiyene truda u pozhilogo cheloveka [Essays on physiology and occupational health in elderly person]. Avicenna: Kyiv, 2007, p 272.

10. Poliakov, O.A. \& Tomarevska, O.S. Otsinka zalyshkovoyi pratsezdatnosti osib, starshykh 60 rokiv [Estimation of residual working capacity in persons 60 years and older. Methodical recommendations (in Ukrainian)]. Kiev, 2016, p 24.

11. Integrated Care for Older People (ICOPE) implementation framework: guidance for system. World Health Organization: Switzerland 2019, p 96. 